\title{
Particle size and endosperm type of dry corn grain altered duodenal flow of B vitamins in lactating dairy cows
}

\author{
D. S. Castagnino, ${ }^{*} \dagger^{1}$ M. Seck, ${ }^{*} \dagger^{2}$ R. A. Longuski, $\ddagger^{3}$ Y. Ying, $\ddagger^{4}$ M. S. Allen, $\ddagger$ R. Gervais, $\dagger$ P. Y. Chouinard, $\dagger$ \\ and C. L. Girard*5 \\ *Agriculture and Agri-Food Canada, Sherbrooke Research and Development Centre, 2000 College, Sherbrooke, QC, Canada, J1M 0C8 \\ †Département des Sciences Animales, Université Laval, 2425 rue de l'Agriculture, Québec, QC, Canada, G1V 0A6 \\ ‡Department of Animal Science, Michigan State University, East Lansing 48824-1225
}

\begin{abstract}
The objective of the experiment was to determine if factors such as endosperm type (floury vs. vitreous) and particle size (fine vs. medium) of dry corn grain, known to affect starch digestibility in the rumen, modify apparent ruminal synthesis and duodenal flow of B vitamins in lactating dairy cows. Eight lactating multiparous Holstein cows equipped with rumen and duodenal cannulas were assigned randomly to a treatment sequence according to a $2 \times 2$ factorial arrangement in duplicate $4 \times 4$ Latin square design experiment. Duration of each experimental period was $21 \mathrm{~d}$. When expressed per unit of dry matter intake (DMI), floury treatments increased duodenal flow and apparent ruminal synthesis of niacin and folates but tended to increase apparent degradation of thiamin in the rumen. Duodenal flow of thiamin, riboflavin, niacin, folates, and vitamin $\mathrm{B}_{12}$, expressed per unit of DMI, decreased with an increase in particle size. Similarly, apparent degradation of thiamin and riboflavin was greater and apparent synthesis of niacin, folates, and vitamin $\mathrm{B}_{12}$ was reduced when cows were fed coarser dry corn grain particles. Neither endosperm type nor particle size had an effect on duodenal flow and apparent ruminal synthesis of vitamin $\mathrm{B}_{6}$. Apparent ruminal syntheses, expressed per unit of DMI, of all studied B vitamins but thiamin were negatively correlated with apparent ruminal digestibility of neutral detergent fiber. Duodenal flow of microbial $\mathrm{N}$ was positively correlated with apparent ruminal synthesis
\end{abstract}

\footnotetext{
Received May 30, 2018.

Accepted July 14, 2018.

${ }^{1}$ Current address: Trouw Nutrition Canada, 4780, rue Martineau, Saint-Hyacinthe, QC, Canada, J2R 1V1.

${ }^{2}$ Current address: Brooke West Africa Office, 5ème étage de l'immeuble sis dans l'impasse, 58 \& 60 Rue Jules Ferry, Dakar, BP 22482, Dakar Ponty, Senegal.

${ }^{3}$ Current address: Department of Large Animal Clinical Sciences, Michigan State University, East Lansing 48824-1601.

${ }^{4}$ Current address: Department of Medicine, Penn Center for Pulmonary Biology, Penn Cardiovascular Institute, University of Pennsylvania, Philadelphia 19104-5159.

${ }^{5}$ Corresponding author: Christiane.Girard@agr.gc.ca
}

of riboflavin, niacin, vitamin $\mathrm{B}_{6}$, and folates. Under the conditions of the present experiment, except for thiamin, the effects of factors increasing starch digestibility of dry corn grain in the rumen on the amounts of $\mathrm{B}$ vitamins available for absorption by the dairy cow seem to be mediated through differences on ruminal digestibility of neutral detergent fiber and, to a lesser extent, on duodenal microbial $\mathrm{N}$ flow.

Key words: dairy cow, B vitamin, corn endosperm, particle size

\section{INTRODUCTION}

Reducing particle size of dry corn grain increases the surface available for microbial attachment (San Emeterio et al., 2000) and accelerates digestion of starch in the rumen (Callison et al., 2001; Rémond et al., 2004). Endosperm type is also a factor affecting the extent of starch digestion in the rumen (Philippeau et al., 1999). The degree of vitreousness in corn grain is correlated with its zein content; this protein, which is the major constituent of protein storage bodies in corn grain, surrounds starch granules and embeds them in a dense matrix (Philippeau et al., 2000; Zhang et al., 2011). The proportion of water-soluble proteins decreases as vitreousness augments (Kotarski et al., 1992). The tight structure of the endosperm of vitreous corn grain reduces ruminal degradability of starch as compared with floury endosperm (Philippeau et al., 2000; Taylor and Allen, 2005a; Lopes et al., 2009), in which no organized pattern exists between protein bodies and starch granules (Philippeau et al., 2000; Zhang et al., 2011). When comparing results from 2 similar studies, Rémond et al. (2004) observed that the effects of particle size on starch digestibility seem to be greater for corn grain with vitreous than that of floury endosperm (Rémond et al., 2004).

It has long been suspected that dietary factors altering abundance and activity of rumen bacterial populations are likely to affect the synthesis of B vitamins (Kon and Porter, 1954; Hayes et al., 1966). Previous studies have 
Table 1. Effects of fineness of grind and endosperm type on particle size of corn grain

\begin{tabular}{lcccccc}
\hline & \multicolumn{2}{c}{ Medium grind } & & \multicolumn{2}{c}{ Fine grind } & \\
\cline { 2 - 3 } Particle size, $\%$ & \multirow{2}{*}{ Vitreous } & Floury & & Vitreous & Floury & \multirow{2}{*}{ SEM } \\
\hline$<600 \mu \mathrm{m}$ & 15.7 & 19.6 & & 15.2 & 21.4 & 2.7 \\
$<1,180 \mu \mathrm{m}$ & 41.9 & 42.7 & & 56.1 & 58.9 & 2.1 \\
$<2,360 \mu \mathrm{m}$ & 97.2 & 93.6 & & 87.4 & 87.1 & 0.8 \\
\hline
\end{tabular}

demonstrated that increasing starch content in the diet by replacing carbohydrate sources (Beaudet et al., 2016) or by increasing the concentrate-to-forage ratio (Seck et al., 2017) decreases ruminal degradation of vitamin $\mathrm{B}_{6}$ and increases ruminal synthesis of riboflavin and folates while decreasing synthesis of vitamin $\mathrm{B}_{12}$ in the rumen. However, differences in starch concentrations in those experimental diets involve many other changes in dietary ingredients or their respective proportions. To our knowledge, with the exception of Hunt et al. (1943), who observed that concentration of riboflavin is greater in the rumen of steers fed ground corn rather than whole corn grain, the effects of starch digestibility on $\mathrm{B}$ vitamin synthesis in the rumen are still unknown.

We hypothesized that factors affecting starch digestibility of dry corn grain in the rumen alter the amounts of B vitamins available for the dairy cow. The objective of our experiment was to define the interactions between endosperm type (floury vs. vitreous) and particle size (fine vs. medium) of dry corn grain on apparent ruminal synthesis and duodenal flow of B vitamins in lactating dairy cows.

\section{MATERIALS AND METHODS}

\section{Animals and Treatments}

Feed and duodenal digesta samples, as well as data on ruminal fermentation, were obtained from an experiment on factors affecting starch digestion conducted at Michigan State University (East Lansing; Allen et al., 2008). Experimental procedures were conducted at Michigan State University following approval by the Institutional Animal Care and Use Committee. Eight lactating multiparous Holstein cows from the Dairy Cattle Teaching and Research Center equipped with rumen and duodenal cannulas were assigned randomly to a treatment sequence according to a $2 \times 2$ factorial arrangement in duplicate $4 \times 4$ Latin square design. At the beginning of the experiment, cows were 132 $(\mathrm{SD}=42.1)$ DIM. The duration of each experimental period was $21 \mathrm{~d}$. The studied factors were endosperm type (floury vs. vitreous) and particle size (fine vs. medium) of dry corn grain. The proportion of vitreousness was 25 and $66 \%$ in endosperm of dry corn grain in the floury and vitreous treatments, respectively. To estimate corn grain vitreousness, 10 whole kernels from each hybrid were weighed, kernels were dissected into germ, pericarp, and vitreous endosperm sections, and individually weighed. Total (floury and vitreous) endosperm weight was determined by subtracting germ and pericarp weight from whole kernel weight, and vitreousness was calculated by dividing vitreous endosperm weight by total endosperm weight. Particle size according to endosperm type is described in Table 1. Medium treatments were ground to match corn grain ground with a Wiley mill with a 6 - $\mathrm{mm}$ screen, and fine treatments were ground to match corn grain ground with a Wiley mill with a 2-mm screen (Arthur H. Thomas, Philadelphia, PA). The treatments (Table 2 ) were offered within a TMR once daily $(1130 \mathrm{~h})$ at $110 \%$ of the expected as-fed intake. Dry corn grain was the major source of starch in the experimental diets formulated for similar forage NDF concentration (18\%) using alfalfa silage as the only forage. Based on ingredient chemical composition, the forage-to-concentrate ratio (\% of DM) was 41:59.

\section{Sample and Data Collection}

Duodenal samples $(1,000 \mathrm{~g})$ were collected every $15 \mathrm{~h}$ from d 10 to 14 , representing every $3 \mathrm{~h}$ of a 24 -h period, and pooled. During each collection period, individual feed intake was recorded daily and TMR samples were collected daily and mixed into a single sample per period. All samples were immediately frozen and stored at $-20^{\circ} \mathrm{C}$ before processing. Freeze-dried samples were kept protected from light at $-20^{\circ} \mathrm{C}$ to minimize potential losses. Under these conditions, vitamin losses were small; vitamin analyses in duodenal samples from the same study conducted 5 yr apart were similar (data not shown).

\section{Laboratory Analyses}

Feed samples were dried in a forced-air oven at $55^{\circ} \mathrm{C}$ for $72 \mathrm{~h}$. Frozen duodenal samples were chopped finely using a commercial food processor (84142 Food Cutter; Hobart Manufacturing Co., Troy, $\mathrm{OH}$ ) and a representative subsample was lyophilized. All samples were ground using a Wiley mill (1-mm screen, Arthur H. 
Thomas). Determination of DM duodenal flow, analyzes for NDF and starch in feed and duodenal samples, and microbial $\mathrm{N}$ were conducted as described by Voelker Linton and Allen (2008).

Thiamin, riboflavin, niacin, and vitamin $\mathrm{B}_{6}$ in feed and duodenal digesta were quantified by HPLC (Varian ProStar, Lake Forest, CA) equipped with a fluorescence detection system (model 363), as described by Castagnino et al. (2016a). Folates were determined with a microbiological microtiter plate test (VitaFast Folic Acid, R-Biopharm Inc., Marshall, MI), and vitamin $\mathrm{B}_{12}$ was analyzed by radioassay [SimulTRAC-S Vitamin $\mathrm{B}_{12}\left({ }^{57} \mathrm{Co}\right) /$ Folate $\left({ }^{125} \mathrm{I}\right)$, MP Biomedicals, Solon, OH], as described by Castagnino et al. (2016a). Dietary Co concentrations were determined by atomic absorption spectrometry with flame stoichiometric air-acetylene at $240.7 \mathrm{~nm}$, as described by Castagnino et al. (2016b) . Samples were analyzed in duplicate (except for folates, which were analyzed in triplicate), and a coefficient of variation of less than $10 \%$ was accepted between replicates.

\section{Calculations and Statistical Analyses}

Daily intake of each vitamin was calculated as the concentration of this vitamin in the TMR (Table 2) multiplied by DMI; DM duodenal flow was calculated as described by Voelker Linton and Allen (2008). Daily $B$ vitamin duodenal flow was calculated as the duodenal DM flow multiplied by B vitamin concentration in the duodenal sample. For each studied vitamin, daily apparent ruminal synthesis was calculated as duodenal flow of the vitamin minus its intake. Intake, duodenal flow, and apparent ruminal synthesis for each vitamin, expressed in milligrams per day or milligrams per kilogram of DMI, were analyzed using SAS mixed model (SAS Institute Inc., 2012), in which periods, treatments, and the endosperm type $\times$ particle size interaction were considered as fixed effects and cows as a random effect. Differences were declared significant at $P<0.05$ and as a tendency at $0.05 \leq P \leq 0.10$. Pearson correlation coefficients were determined between apparent ruminal synthesis of B vitamins and apparent ruminal digestibility of starch and NDF and duodenal flow of microbial $\mathrm{N}$ using individual values for each cow in each treatment.

\section{RESULTS AND DISCUSSION}

Diets based on dry corn with a floury endosperm had no effect $(P=0.13)$ on DMI but decreased $(P=0.01)$ DM duodenal flow; DMI and DM duodenal flow were

Table 2. Ingredients and chemical composition of the basal ration and concentrations of Co and B vitamins in experimental diets according to endosperm type and particle size of dry corn grain

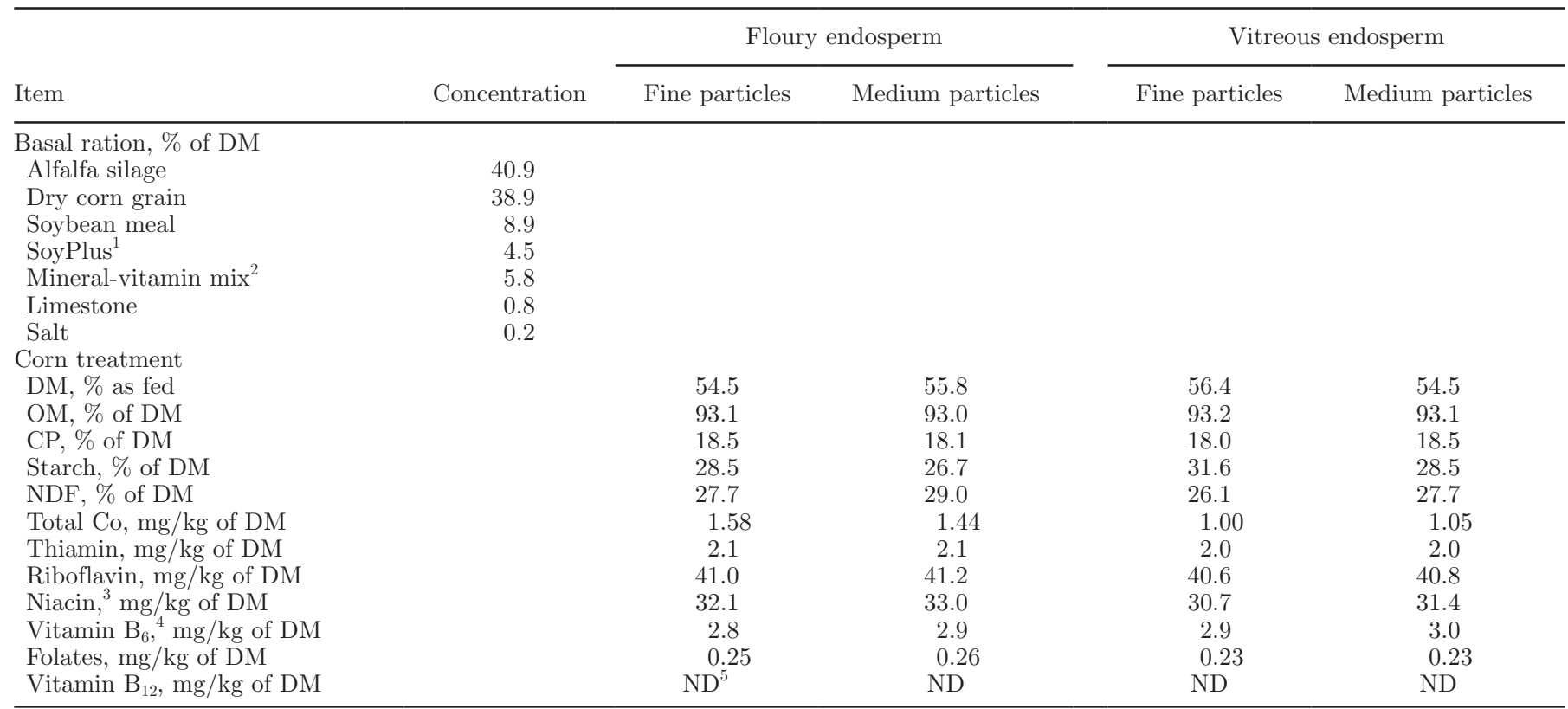

${ }^{1}$ West Central Soy, Ralston, IA.

${ }^{2}$ Vitamin-mineral mix contained (on a DM basis) $69.4 \%$ ground corn, $18.5 \%$ sodium bicarbonate, $4.2 \%$ dicalcium phosphate, $2.8 \%$ magnesium oxide, $2.1 \%$ salt, $2.1 \%$ trace minerals, $0.446 \%$ vitamin A, $0.411 \%$ vitamin D, and $0.182 \%$ vitamin E. Analyzed Co: $6.34 \mathrm{mg} / \mathrm{kg}$ of DM.

${ }^{3}$ Sum of nicotinic acid and nicotinamide.

${ }^{4}$ Sum of pyridoxamine, pyridoxal, and pyridoxine.

${ }^{5}$ Not detected. 
25.3 and $26.3(\mathrm{SE}=1.46) \mathrm{kg} / \mathrm{d}$ and 17.0 and $19.8(\mathrm{SE}$ $=1.25) \mathrm{kg} / \mathrm{d}$ for floury and vitreous treatments, respectively. Neither particle size nor its interaction with endosperm type had an effect on DMI or DM duodenal flow $(P \geq 0.48)$. Results from the present experiment are in accordance with those reported in the literature, that reducing particle size of dry corn grain has had no effect on DMI (Callison et al., 2001; Rémond et al., 2004; Eastridge et al., 2011). Effects of endosperm type on DMI seem more variable; decreasing vitreousness of dry corn grain endosperm decreased DMI with a diet based on normal corn silage, whereas it had no effect when the diet contained brown midrib 3 corn silage. This difference was explained by changes in feeding behavior (i.e., number, length, and size of meals; Taylor and Allen, 2005b).

Floury treatments decreased $(P \leq 0.04)$ only riboflavin and vitamin $\mathrm{B}_{6}$ intakes (Table 3 ). Daily duodenal flow and apparent ruminal synthesis of folates were greater $(P=0.004)$ when cows were fed the floury treatments (Table 3). When expressed per unit of DMI, floury treatments increased $(P \leq 0.04)$ duodenal flow and apparent ruminal synthesis of niacin and folates, but tended to increase $(P=0.10)$ apparent degrada- tion of thiamin in the rumen (Table 4). Duodenal flow of thiamin, riboflavin, niacin, folates, and vitamin $\mathrm{B}_{12}$, expressed as total daily amount or per unit of DMI, decreased or tended to decrease $(P \leq 0.08)$ with an increase in particle size (Tables 3 and 4). Similarly, when expressed in milligrams per day or milligrams per kilogram of DMI, apparent degradations of thiamin $(P$ $=0.09$ and 0.08$)$ and riboflavin $(P=0.08$ and 0.04$)$ were greater or tended to be greater, and apparent syntheses of niacin $(P=0.04$ and 0.03$)$, folates $(P=$ 0.0006 and 0.0005$)$, and vitamin $\mathrm{B}_{12}(P=0.02$ and $0.03)$ were reduced when cows were fed coarser dry corn grain particles (Tables 3 and 4). When expressed per unit of DMI, the decrease in apparent synthesis of folates in the rumen when increasing particle size tended to be greater with the floury treatments (interaction endosperm $\times$ particle size, $P=0.10$ ). Neither endosperm type nor particle size had an effect on duodenal flow and apparent ruminal synthesis of vitamin $\mathrm{B}_{6}(P$ $\geq 0.19$; Tables 3 and 4 ).

Both studied factors, endosperm type and particle size, are known to affect starch digestibility of corn grain in the rumen (Rémond et al., 2004; Taylor and Allen, 2005a). In the present experiment, decreasing

Table 3. Effects of endosperm type and particle size of dry corn grain on B vitamin intake, duodenal flow (DF), and apparent ruminal synthesis (ARS), expressed as milligrams per day, of lactating dairy cows ${ }^{1}$

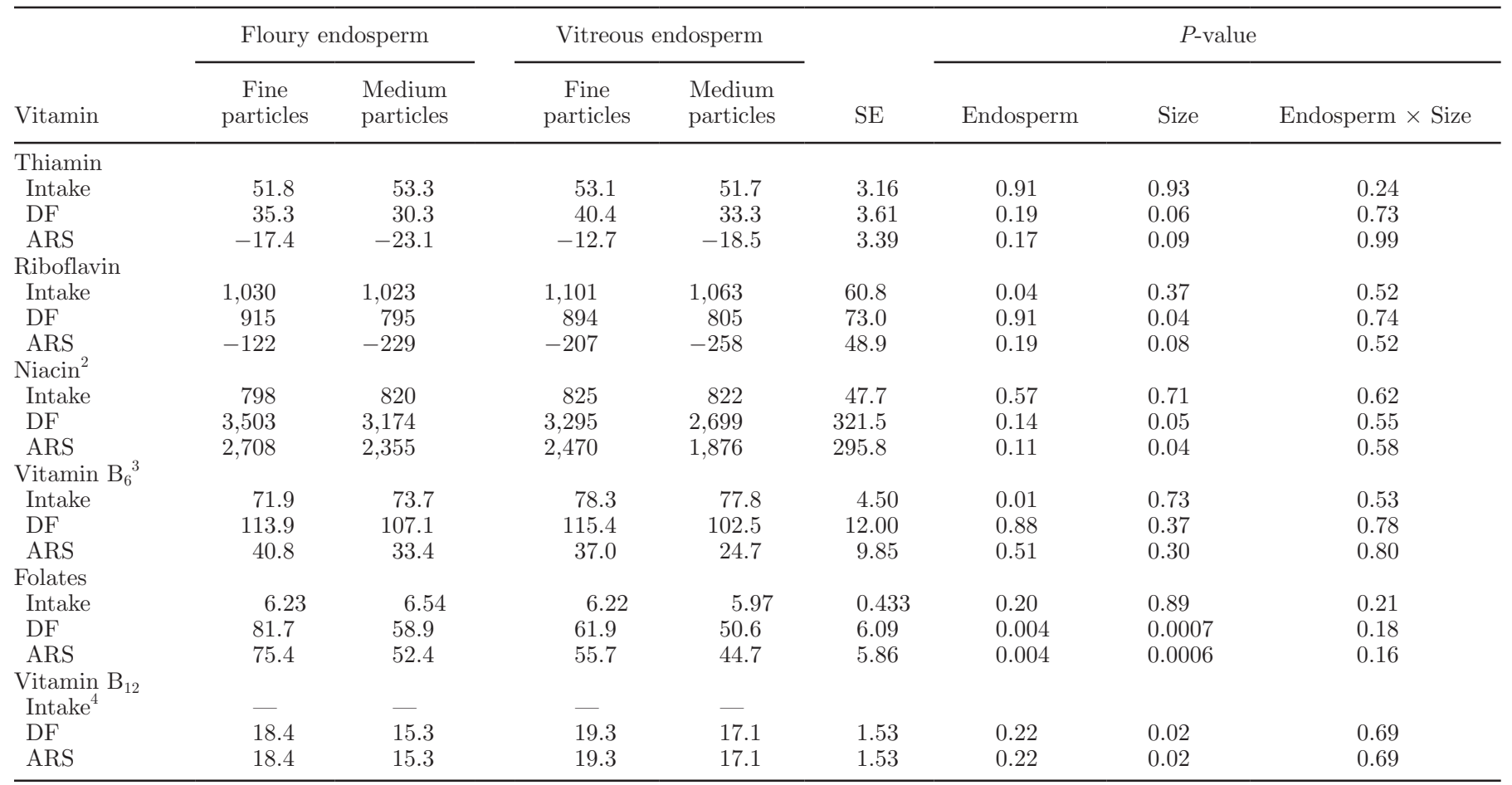

${ }^{1}$ Least squares means.

${ }^{2}$ Sum of nicotinic acid and nicotinamide.

${ }^{3}$ Sum of pyridoxamine, pyridoxal and pyridoxine.

${ }^{4}$ Not detected. 
Table 4. Effects of endosperm type and particle size of dry corn grain on B-vitamin duodenal flow (DF) and apparent ruminal synthesis (ARS), expressed as milligrams per kilogram of DMI, of lactating dairy cows ${ }^{1}$

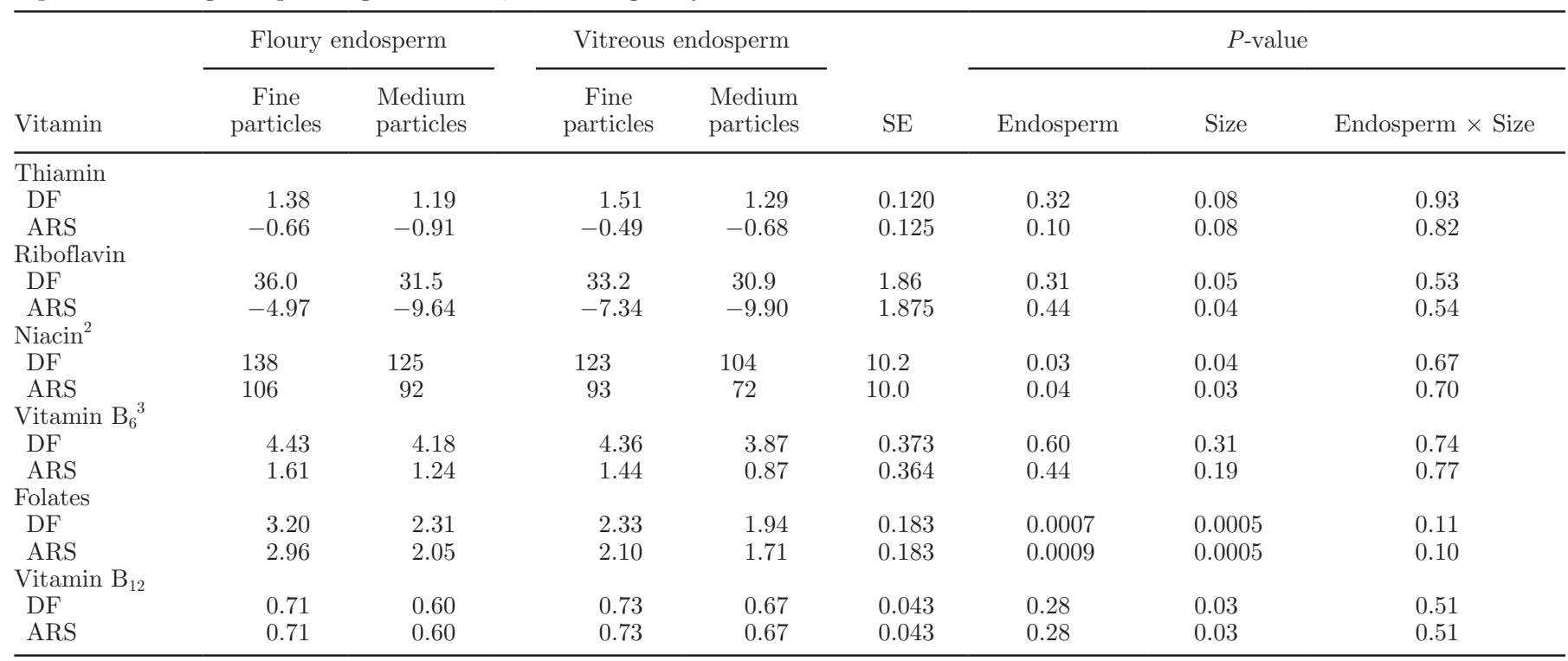

${ }^{1}$ Least squares means.

${ }^{2}$ Sum of nicotinic acid and nicotinamide.

${ }^{3}$ Sum of pyridoxamine, pyridoxal, and pyridoxine.

vitreousness of corn endosperm had a greater effect on starch digestibility in the rumen than decreasing particle size, increasing it by 118 and $52 \%$, respectively (Allen et al., 2008). Nevertheless, endosperm type had limited effect on B vitamin duodenal flow and apparent ruminal synthesis as compared with particle size. Moreover, in the present study, we found no correlation $(P \geq 0.15)$ between apparent digestibility of starch in the rumen and apparent ruminal synthesis of the studied vitamins, expressed per unit of DMI (Table 5) or milligrams per day (data not shown). However, apparent ruminal syntheses of all studied B vitamins but thiamin were or tended to be negatively correlated $(P \leq 0.07)$ with apparent ruminal digestibility of NDF. In line with this observation, negative correlations were previously reported between the amount of
NDF digested in the rumen and apparent synthesis of riboflavin (Beaudet et al., 2016; Castagnino et al., 2017; Seck et al., 2017), vitamin $\mathrm{B}_{6}$, (Castagnino et al., 2017; Seck et al., 2017), and niacin (Seck et al., 2017). Duodenal flow of microbial N was or tended to be positively correlated $(P \leq 0.09)$ with apparent synthesis of riboflavin, niacin, vitamin $\mathrm{B}_{6}$, and folates in the rumen (Table 5). Similarly, positive correlations were observed in previous experiments between the duodenal flow of microbial $\mathrm{N}$ and apparent ruminal synthesis of riboflavin, niacin, and folates (Castagnino et al. 2016a; Seck et al., 2017). Consistent with these results, Beaudet et al. (2016) observed positive correlations between the efficiency of bacterial synthesis and apparent ruminal synthesis of these latter $3 \mathrm{~B}$ vitamins.

Table 5. Pearson correlation coefficients between apparent ruminal synthesis of B vitamins and apparent ruminal digestibility of starch and $\mathrm{NDF}$ and duodenal flow of microbial N

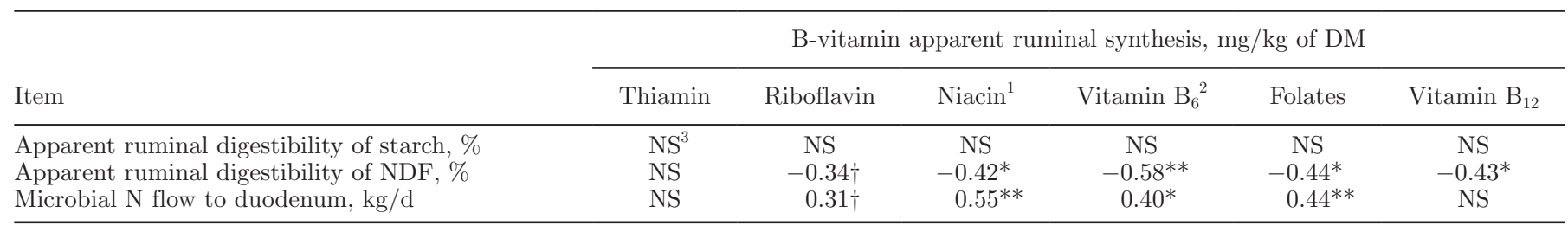

${ }^{1}$ Sum of the molar concentrations of nicotinic acid and nicotinamide.

${ }^{2} \mathrm{Sum}$ of the molar concentrations of pyridoxamine, pyridoxal, and pyridoxine.

${ }^{3} \mathrm{NS}=$ not significant, $P>0.10$.

$\dagger P \leq 0.10 ;{ }^{*} P<0.05 ;{ }^{*} P<0.01$. 
Increasing starch digestion in the rumen reduces ruminal digestion of NDF (Callison et al., 2001; Firkins et al., 2001) and is expected to increase microbial $\mathrm{N}$ flow (Firkins et al., 2001). However, the amplitude of the later response could be altered by changes in NDF digestibility in the rumen (Callison et al., 2001). In the present experiment, even if endosperm type had a greater effect on starch digestibility than particle size, the latter affected B vitamin synthesis in the rumen to a greater extent. These results suggest that the treatment effects observed in the present experiment on B vitamin synthesis were probably not mediated directly by starch ruminal digestibility. Under the conditions of the present experiment, except for thiamin, the fate of $\mathrm{B}$ vitamins in the rumen was possibly driven by differences in ruminal digestibility of NDF and, to a lesser extent, in microbial $\mathrm{N}$ flow at the duodenum, both potentially induced by changes in starch ruminal digestibility.

\section{ACKNOWLEDGMENTS}

The authors thank Chrystiane Plante and Valérie Beaudet (Sherbrooke Research and Development Centre, Agriculture and Agri-Food Canada, Sherbrooke, QC, Canada) for their technical support. Vitamin analyses were financially supported by the Programme de recherche en partenariat pour l'innovation en production et transformation laitière Novalait, Agriculture et Agroalimentaire Canada, Fonds de recherche du Québec Nature et Technologies, Ministère de l'Agriculture, des Pêcheries et de l'Alimentation du Québec, Québec, QC, Canada.

\section{REFERENCES}

Allen, M. S., R. A. Longuski, and Y. Ying. 2008. Endosperm type of dry ground corn grain affects ruminal and total tract digestion of starch in lactating dairy cows. J. Dairy Sci. 91(E-Suppl. 1):529. (Abstr.)

Beaudet, V., R. Gervais, B. Graulet, P. Nozière, M. Doreau, A. Fanchone, D. D. S. Castagnino, and C. L. Girard. 2016. Effects of dietary nitrogen levels and carbohydrate sources on apparent ruminal synthesis of some B vitamins in dairy cows. J. Dairy Sci. 99:2730-2739. https://doi.org/10.3168/jds.2015-10521.

Callison, S. L., J. L. Firkins, M. L. Eastridge, and B. L. Hull. 2001. Site of nutrient digestion by dairy cows fed corn of different particle sizes or steam-rolled. J. Dairy Sci. 84:1458-1467. https://doi .org/10.3168/jds.S0022-0302(01)70179-8.

Castagnino, D. S., K. L. Kammes, M. S. Allen, R. Gervais, P. Y. Chouinard, and C. L. Girard. 2016b. Particle length of silages affects apparent ruminal synthesis of B vitamins in lactating dairy cows. J. Dairy Sci. 99:6229-6236. https://doi.org/10.3168/jds.2016 -11274 .

Castagnino, D. S., K. L. Kammes, M. S. Allen, R. Gervais, P. Y. Chouinard, and C. L. Girard. 2017. High-concentrate diets based on forages harvested at different maturity stages affect ruminal syn- thesis of B vitamins in lactating dairy cows. Animal 11:608-615. https://doi.org/10.1017/S1751731116001798.

Castagnino, D. S., M. Seck, V. Beaudet, K. L. Kammes, J. A. Voelker Linton, M. S. Allen, R. Gervais, P. Y. Chouinard, and C. L. Girard. 2016a. Effects of forage family on apparent ruminal synthesis of B vitamins in lactating dairy cows. J. Dairy Sci. 99:1884-1894. https://doi.org/10.3168/jds.2015-10319.

Eastridge, M. L., A. H. Lefeld, A. M. Eilenfeld, P. N. Gott, W. S. Bowen, and J. L. Firkins. 2011. Corn grain and liquid feed as nonfiber carbohydrate sources in diets for lactating dairy cows. J. Dairy Sci. 94:3045-3053. https://doi.org/10.3168/jds.2010-3908.

Firkins, J. L., M. L. Eastbridge, N. R. St-Pierre, and S. M. Noftsger. 2001. Effects of grain variability and processing on starch utilization by lactating dairy cattle. J. Anim. Sci. 79(Suppl. 1):E218E238. https://doi.org/10.2527/jas2001.79E-SupplE218x.

Hayes, B. W., G. E. Mitchell Jr., C. O. Little, and N. W. Bradley. 1966. Concentrations of B-vitamins in ruminal fluid of steers fed different levels and physical forms of hay and grain. J. Anim. Sci. 25:539-542. https://doi.org/10.2527/jas1966.252539x.

Hunt, C. H. E. W. Burroughs, R. M. Bethke, A. F. Schalk, and P. Gerlaugh. 1943. Further studies on riboflavin and thiamine in the rumen content of cattle. II. J. Nutr. 25:207-216.

Kon, S. K., and J. W. G. Porter. 1954. The intestinal synthesis of vitamins in the ruminant. Vitam. Horm. 12:53-68. https://doi.org/ 10.1016/S0083-6729(08)61008-0.

Kotarski, S. F., R. D. Waniska, and K. K. Thurn. 1992. Starch hydrolysis by the ruminal microflora. J. Nutr. 122:178-190.

Lopes, J. C., R. D. Shaver, P. C. Hoffman, M. S. Akins, S. J. Bertics, H. Gencoglu, and J. G. Coors. 2009. Type of corn endosperm influences nutrient digestibility in lactating dairy cows. J. Dairy Sci 92:4541-4548. https://doi.org/10.3168/jds.2009-2090.

Philippeau, C., F. de Deschault de Monredon, and B. Michalet-Doreau. 1999. Relationship between ruminal starch degradation and the physical characteristics of corn grain. J. Anim. Sci. 77:238-243. https://doi.org/10.2527/1999.771238x.

Philippeau, C., J. Landry, and B. Michalet-Doreau. 2000. Influence of the protein distribution of maize endosperm in ruminal starch degradability. J. Sci. Food Agric. 80:404-408.

Rémond, D., J. I. Cabrera-Estrada, M. Champion, B. Chauveau, R Couture, and C. Poncet. 2004. Effect of corn particle size on site and extent of starch digestion in lactating dairy cows. J. Dairy Sci. 87:1389-1399. https://doi.org/10.3168/jds.S0022-0302(04)73288 $-9$.

San Emeterio, F., R. B. Reis, W. E. Campos, and L. D. Satter. 2000. Effect of coarse or fine grinding on utilization of dry or ensiled corn by lactating dairy cows. J. Dairy Sci. 83:2839-2848. https:/ doi.org/10.3168/jds.S0022-0302(00)75184-8.

SAS Institute Inc. 2012. User's Guide: Statistics. Version 9.4. SAS Institute Inc., Cary, NC.

Seck, M., J. A. Voelker Linton, M. S. Allen, D. S. Castagnino, P. Y. Chouinard, and C. L. Girard. 2017. Apparent ruminal synthesis of B vitamins in lactating dairy cows fed diets with different forage-to-concentrate ratios. J. Dairy Sci. 100:1914-1922. https:// doi.org/10.3168/jds.2016-12111.

Taylor, C. C., and M. S. Allen. 2005a. Corn grain endosperm type and brown midrib 3 corn silage: site of digestion and ruminal digestion kinetics in lactating cows. J. Dairy Sci. 88:1413-1424. https://doi .org/10.3168/jds.S0022-0302(05)72809-5.

Taylor, C. C., and M. S. Allen. 2005b. Corn grain endosperm type and brown midrib 3 corn silage: feeding behavior and milk yield of lactating cows. J. Dairy Sci. 88:1425-1433. https://doi.org/10 .3168/jds.S0022-0302(05)72810-1.

Voelker Linton, J. A., and M. S. Allen. 2008. Nutrient demand interacts with forage family to affect intake and digestion responses in dairy cows. J. Dairy Sci. 91:2694-2701. https://doi.org/10.3168/ jds.2007-0897.

Zhang, H., R. Gao, and S. Dong. 2011. Anatomical and physiological characteristics associated with corn endosperm texture. Agron. J. 103:1258-1264. https://doi.org/10.2134/agronj2010.0212. 